\title{
Building institutional capability in e-learning design
}

\author{
Gilly Salmon ${ }^{\mathrm{a}}$, Sylvia Jones ${ }^{\mathrm{b}}$ and Alejandro Armellini ${ }^{\mathrm{a} *}$ \\ ${ }^{a}$ Beyond Distance Research Alliance, University of Leicester, UK; ${ }^{b}$ Institute of Educational \\ Technology, Open University, Milton Keynes, UK
}

\begin{abstract}
We detail the research, development and initial outcomes of an intervention process to promote capability building in designing for e-learning at a dual mode university in the UK. The process, called CARPE DIEM, was built on a pilot study and became a Higher Education Academy 'Pathfinder' project named ADELIE. We report on the model workshop, its deployment, research and development over a 12-month period with a variety of subject groups working in small teams with learning technologists, pedagogical facilitators and librarians. Outcomes include improved scores on an institutional e-learning benchmarking exercise and increased capability for designing for online activities for students in the Virtual Learning Environment (VLE). The model is stable enough to be tried in other institutions and continues to develop in scope.
\end{abstract}

Keywords: e-learning design; capability; pathfinder; team working; CARPE DIEM model

\section{The context and the challenge}

The University of Leicester in the UK has many characteristics of a traditional campusbased university, including a high skills base of face-to-face lecturing and an autonomous departmental structure. In addition to its 12,000 campus-based undergraduates, Leicester has a thriving set of distance learning programmes serving around 7,200 students. Although the university is research-led, its teaching is popular with students, achieving high completion rates and top ranking over the three years of The National Student Survey (thestudentsurvey.com).

A Virtual Learning Environment (VLE, Blackboard) was introduced by the IT department and supported by the Staff Development Unit from 2002, but without a strategic plan for using learning technologies or any deliberate revision of pedagogical approaches. The VLE was used at first only by innovators and early adopters among the staff (Hannan 2005). Students' responses to learning via the VLE varied.

However, the university soon recognised that increased VLE use by both campus and distance students could support and extend its traditional ways of learning and teaching, and introduce productive, positive changes in students' learning experiences. There was neither a crisis nor a serious problem to solve, but a strategic intent to adopt appropriate technologies and pedagogical approaches, thus building on Leicester's success in teaching and research.

In 2004, the university created a Chair to raise the profile of e-learning, exploit learning technologies and positively impact on the student learning experience across all modes of learning and disciplines. In 2005, the university's Senate accepted and resourced an e-learning and pedagogical innovation strategy (Salmon 2005), aligned with the Higher

*Corresponding author. Email: alejandro.armellini@le.ac.uk 
Education Funding Council for England (HEFCE) e-learning strategy of March 2005 (HEFCE 2005). The university's e-learning strategy was to promote pedagogical innovation, increase deployment of learning technologies and enable research into e-learning in a way that directly addressed business opportunities and imperatives. It provided for equivalent and enhanced learning and support experiences for all the university's students, regardless of their modes of study. It offered a framework to deepen understanding and deployment of learning technologies within the university. Although aware of the debate between centralised provision and devolution of academic development (Hunt 2006), the university felt that departmental autonomy should be acknowledged and valued. Academics were to be encouraged with support and evidence for the changes rather than receiving a central directive. There was no obvious central unit such as a technology centre to provide a lead. The strategy provided for a research unit to provide evidence and guide change, working with the IT services, Staff Development and the Library.

\section{Implementing strategy}

In 2005, the university began implementing its new e-learning and pedagogical innovation strategy (Salmon 2005). The framework for the academic development needed is based on a 'resource' definition of change (Salaman and Asch 2003), focusing on developing capability for different purposes through collaborative effort. Such a framework implies identifying the institution's core capabilities and existing strengths (what it is good at, what makes it special), and how a strategy can take advantage of these in a competitive world (what can it do well and differently?).

Leicester believed that its e-learning and pedagogical innovation strategy, if based on those kinds of strengths, would be more durable and harder to imitate, than 'off-theshelf' strategies (Hamel and Valikangas 2003) or those based on a traditional market-led approach (Salaman and Asch 2003). The strategy also acknowledges the importance of the university's characteristics and context. It focuses on awareness of the pedagogical potential of learning technologies and of design for learning (Laurillard 2007). One of the strategy's four parts is aimed at building the institution's existing skill base of learning and teaching with stable technologies such as the VLE, whilst the others look towards outreach work; exploitation of Web 2.0 and personal devices; and futures forecasting (Salmon 2005).

\section{Choices for academic support for e-learning}

The reluctance of some university teachers to embrace change in their pedagogy, whether associated with e-learning or other initiatives, is well documented (Sharpe, Benfield, and Francis 2006; Flemming and Rutherford 1985). Academics tend to think of issues relating to learning, teaching and assessment in terms of their own discipline - their own 'tribe and territory' (Becher and Trowler 2001, 1). This strong disciplinary focus, arising from epistemological and social sources, can inhibit acceptance of change (Becher and Trowler 2001). Academics work within the dominant discourse about teaching in their discipline and may be antipathetic to staff development, advice or theory or research which is not disciplinebased (Jenkins 1996). Others are keen to try out new technologies but 'unsympathetic to centrally determined initiatives and unable to gain support for their own ideas' (Hannan 2005, 981).

Dual mode universities like Leicester present special challenges (Ask 2007). Whilst campus teaching succeeds well within the autonomy of faculties, departments and teachers, 
teaching at a distance needs longer term, operational management (Renwick 1992). At Leicester, distance learning emerged from and was embedded in 12 different departments; strenuous efforts are necessary to achieve economies of scale through support systems.

Leicester's framework for implementing e-learning therefore needed to be pedagogically driven rather than technology-led (Laurillard 2007), flexible enough to incorporate new leading-edge technologies and rooted in disciplinary practice. Where distance learning was involved, preparation needed to include 'design once, deliver to many' (Renwick 1992). The strategy encompassed and promoted a contextualised, complex view of the value of e-learning (Salmon 2005), to meet the university's objectives. The strategy needed to accommodate new learning technologies including those not originally designed for learning, such as student-owned devices such as iPods and PDAs (Salmon and Nie 2008).

\section{The benchmarking exercise}

The Beyond Distance Research Alliance (BDRA), charged with developing and supporting learning innovation in the university, was established in parallel with the e-learning strategy. A year after the strategy's launch, BDRA worked on an e-learning benchmarking exercise, supported by the Higher Education Academy's (henceforth 'Academy') Pilot Phase of the Pathfinder Programme. The exercise provided quantitative and qualitative information on how far institutions are embedding different aspects of e-learning into institutional policy and practice. The first benchmarking at the University of Leicester, February-June 2006, was supported by an Academy-provided expert consultant. An internal steering group guided data-collection and analysis. Scores were established by a university-wide team. 'Instructional design \& pedagogy' and 'learning materials' were issues on which the university scored lower than on other criteria. A second benchmarking exercise, using the same criteria and measures, took place from March-July 2007. See Table 1 for details and scores. In 2006 each benchmarking criterion was scored on a scale of $1-5$, with 1 designating baselevel activity and 5 designating maximum activity. In 2007 the scale was 1-6, with 6 as 'excellence', 'transcendence', or 'second wave' situations in the sector. The change was introduced by the developers (Matic Media Ltd, http:/www.matic-media.co.uk/). Benchmarking was recognised as an efficient way to evaluate the effectiveness of the university's e-learning strategy and the progress made in the intervening period.

The benchmarking results suggested that the VLE and other stable and highly supported technologies such as the digital library were not being used as effectively as they could be by most academic staff. The university subsequently decided to build the capability of its academic staff to understand and practise designing for learning. Design bridges theory and practice (Beetham and Sharpe 2007), and can be acquired and built upon by small teams. The university also needed the quickest possible interventions that 'made a difference' to student learning, given that academics' time is limited: teaching competes with research and administrative duties.

The challenge for BDRA was to develop capability in e-learning design that would engage Leicester's academics. BDRA had to enthuse them to build on good practice, adapting their own practice to new modes of learning and forms of learning technologies. BDRA wanted to 'beguile' and entice the academics, persuading them to engage with student learning activities on the VLE, work together and work with others who could help them. Each intervention needed to be appropriate for a variety of different disciplines and modes of learning, and yet had to keep responsibility within the subject team. It had to fit the autonomous cultures and structures at Leicester but also contribute to building capability in e-learning. 
Table 1. E-learning benchmarking: pick and mix criteria.

\begin{tabular}{|c|c|c|c|c|}
\hline No. & Factor & $\begin{array}{l}2006 \text { benchmarking } \\
\text { scores (on a scale of } \\
1-5 \text { ) }\end{array}$ & $\begin{array}{c}2007 \text { benchmarking } \\
\text { scores (on a scale of } \\
1-6 \text { ) }\end{array}$ & Progression \\
\hline 1 & Adoption & 5.0 & 6.0 & 1.0 \\
\hline 2 & VLE Stage & 4.0 & 4.5 & 0.5 \\
\hline 3 & Tools & 5.0 & 6.0 & 1.0 \\
\hline 4 & Usability & 1.0 & 2.0 & 1.0 \\
\hline 5 & Accessibility & 3.5 & 3.6 & 0.1 \\
\hline 6 & e-Learning Strategy & 4.0 & 6.0 & 2.0 \\
\hline 7 & Decisions (Projects) & 4.0 & 5.2 & 1.2 \\
\hline 8 & Pedagogy & 2.0 & 3.5 & 1.5 \\
\hline 9 & Learning Material & 3.0 & 3.5 & 0.5 \\
\hline 10 & Training & 4.0 & 4.5 & 0.5 \\
\hline 11 & Academic Workload & 3.0 & 4.0 & 1.0 \\
\hline 12 & Costs & 4.0 & 4.0 & 0.0 \\
\hline 13 & Planning (Annual) & 3.0 & 4.5 & 1.5 \\
\hline 14 & Evaluation & 4.0 & 4.0 & 0.0 \\
\hline 15 & Organisation & 5.0 & 5.0 & 0.0 \\
\hline 16 & Technical Support to Staff & 4.0 & 5.0 & 1.0 \\
\hline 17 & Quality Assurance & 4.0 & 5.0 & 1.0 \\
\hline 18 & Staff Recognition \& Reward & 3.0 & 4.5 & 1.5 \\
\hline 55 & Foresight & 5.0 & 6.0 & 1.0 \\
\hline 58 & Market Research & 3.0 & 3.0 & 0.0 \\
\hline 59 & Competitor Research & 1.0 & 2.0 & 1.0 \\
\hline 63 & Leverage & 2.5 & 4.0 & 1.5 \\
\hline 68 & Research Outputs & 4.0 & 4.0 & 0.0 \\
\hline 91 & Student Understanding of System & 3.0 & 4.0 & 1.0 \\
\hline 94 & Student Satisfaction & 3.0 & 4.0 & 1.0 \\
\hline
\end{tabular}

\section{Background to the intervention}

The intervention is through a workshop, called CARPE DIEM, designed to encourage small teams to work together on e-learning design using a VLE. The two-day workshop offers academics, for a small commitment in time, quick realisation of their investment in learning design. The CARPE DIEM workshop model (see Figure 1) is based on story boarding (Tumminello 2004), team working (Jaques and Salmon 2006), scaffolding of networked learning, especially Salmon's 5-stage model and e-tivities (Salmon 2002) and aligned assessment (Biggs and Tang 2007). It involves six sequential progressive collaborative tasks, led by a trained facilitator familiar with the process. Day 1 is a visioning and planning day (no computers); day 2 deploys the VLE.

CARPE DIEM workshops began in 2002 at Caledonian Business School, Glasgow Caledonian University, when it introduced a VLE (Blackboard). Feedback from participating staff from the first three workshops (Salmon 2003, 2004), plus feedback from students when the courses were first presented (Siddiqui and Roberts 2004), indicated that:

- students were on the whole engaged and happy with the e-tivities they were offered, ones that had been developed during the workshops; 


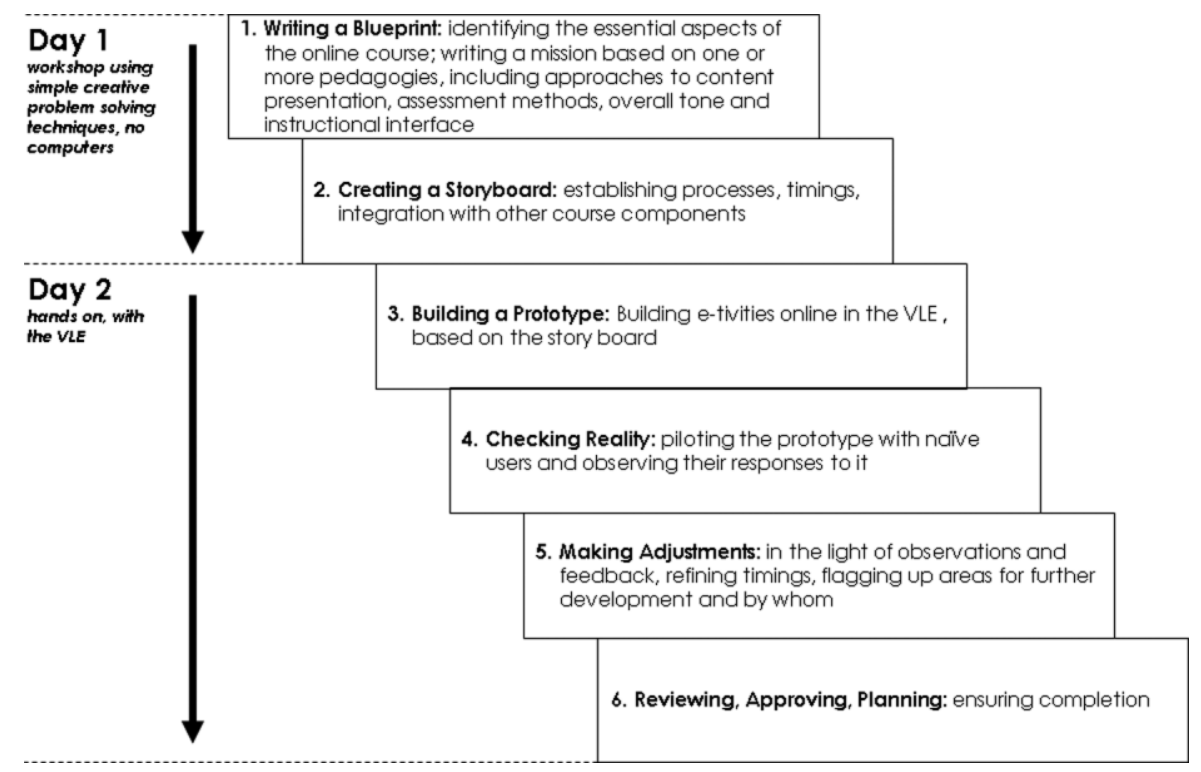

Figure 1. The CARPE DIEM workshop model.

- there was visible confidence building among academics in using the VLE for student activities;

- the team approach resulted in better professional relationships, which were sustained after the intervention;

- the CARPE DIEM model was stable enough to be tried by others, and for facilitators to be trained.

Further testing and transfer with subject teams at the University of Bournemouth and Anglia Ruskin University resulted in increased understanding of and adjustments to the model, and its adoption by others such as Kingston University (Malone 2004).

\section{Project ADELIE: intervention and research}

In October 2006, a research and development pathfinder project called ADELIE (Advanced Design for E-Learning Institutional Embedding) was set up in BDRA at Leicester. Pathfinder projects were Academy-funded and followed on from e-learning benchmarking. They offered HEIs an opportunity to try a transformation initiative with organisational change, development and dissemination as core aims. Similar interventions include the University of Hertfordshire's CABLE project (Anderson et al. 2008) and Oxford Brookes' Intensives (Benfield 2008).

ADELIE was independent of routine staff development and had the flexibility for BDRA to forge a partnership for design (rather than a training or development relationship) with participants in various disciplines. It was important that academic teaching staff felt in control of discipline-related aspects of the design and that the specific learning requirements for their discipline were reflected in their designs. As an intervention, ADELIE offered CARPE DIEM sessions for designing both on-campus and distance e-learning courses. By October 2007, the ADELIE team had worked through the CARPE DIEM process with 16 course teams in 11 disciplines. 
The university chose CARPE DIEM as the intervention to address issues of capability building in e-learning design across different disciplines and modes of learning. CARPE DIEM offered important capability building for Leicester, that could support the prevailing cultures and thus be accepted:

- Discipline-based teams are invited to take part. CARPE DIEM is not seen as staff development, but a supportive academic activity. Other professions in the university are brought in to work with the subject teams. CARPE DIEM participants include a facilitator with pedagogical knowledge, a subject librarian, a learning technologist plus the subject specialists. All course team members and other professionals are expected to be present and participate throughout the two-day workshop.

- A trained facilitator leads the workshop using the CARPE DIEM model and process, and pre-prepared activities and resources, to make the most of the team's time together.

- The workshop is centred on a new course, or one transferred from a different mode of learning to incorporate new technologies or approaches. The curriculum and learning outcomes are agreed by the subject group before arrival in the workshop. Inevitably some discussions on content ensue but the CARPE DIEM facilitator helps prevent content discussions dominating pedagogical ones.

- The intervention is focused on practical and contextualised outcomes for one particular course, module or programme team. Although the workshops complement individual staff development activities, they are clearly distinguished from them by promising to 'get your course online - together'.

- Only stable 'tried and tested' technologies are used so that the focus can shift to pedagogy and the learning experience as soon as possible. Typically these were the VLE and the digital library, although wikis and podcasting are now being tried.

- No computers are used until a 'blueprint' and 'storyboard' are agreed by the team.

Other related activities continued in the university. The Staff Development Unit continued to build on their learning technology and e-learning courses and IT and systems provision was scaled up. The Media Zoos were established for sharing learning technology research outcomes and providing 'safe' environments for staff to experiment with learning technologies (www.le.ac.uk/beyonddistance/mediazoo). Learning technology seminars and an annual local conference were established.

\section{ADELIE as research}

Running alongside the intervention was a research study aimed at establishing whether CARPE DIEM is an appropriate tool for capability building in e-learning design at Leicester, testing the intervention model in various disciplines and with different kinds of professional teams. The study was developed as action research (Lomax 1994) rooted in the context of higher education (Eden and Husham 1996). Bhattacharya, Cowan, and Weedon (2000) demonstrate that action research in educational settings offers opportunities for incorporating feedback and evaluation into change processes, and can lead to generalisable models.

The CARPE DIEM model and the intervention process evolved through analysis of participants' feedback. This paper reports on the viability, scalability and enhancement of the model and evidence of capability building amongst academics in the University 
of Leicester. Armellini and Jones (2008) report on pedagogical developments from the research.

Three approaches were employed for collecting data:

- Observations of meetings and workshops in the form of notes and recordings;

- Semi-structured interviews with participants from subject groups involved in CARPE DIEM workshops;

- Collection of artefacts in the form of course designs and e-tivities produced during and after the workshops.

Departments taking part knew that ADELIE was a research as well as a development project and agreed to participate on this basis. Specifically, they agreed to observations and records being made of all aspects of their participation before, during and after the CARPE DIEM workshops, including reference to the e-learning designs they produced. Individual members of the course teams agreed to take part in semi-structured interviews before and after the CARPE DIEM workshops. The names of individuals have been removed here and the names given to course teams have been generalised to indicate a discipline rather than a specific course, to preserve anonymity.

The research was designed so that the ADELIE team members were able to review and evaluate the process and make changes in the CARPE DIEM model throughout its implementation. A protocol for observing the workshops recorded the course teams' engagement with the activities, critical incidents, values and practices around course development and evidence of capability building.

The ADELIE interview schedule consisted of two semi-structured interviews with a volunteer from each participating course team. Volunteers included course leaders and tutors. Interviews lasted 45 minutes and occurred one month before and six weeks after participation in the CARPE DIEM workshop. The pre-CARPE DIEM interviews probed the individual's typical uses of and attitudes towards e-learning and the common e-learning practices within that person's course team. The questioning revealed motivations for attending CARPE DIEM and what the participant envisaged would be the benefit to course design. The post-CARPE DIEM interviews probed for what was learned in the workshop and investigated how individual and team learning might translate into capability building.

Interview and observation transcripts were analysed using QSR N6 software. The range and sequence of this data collection, plus the analysis of e-learning designs produced by participants during and after the workshops, made it possible to establish and track changes in capability.

\section{Revising the CARPE DIEM model}

Soon after ADELIE started, it became clear that the two-day CARPE DIEM workshop alone was insufficient for full engagement with course teams. Participants needed very good reasons to clear two days of their diaries. Trust in the ADELIE team and a full understanding of the purpose and expected outcomes of the workshop were essential for engaging and motivating course teams. Contact meetings before the workshops were added to ensure that the two workshop days were truly 'seized' for designing for learning. Interview data suggested that a follow-up meeting for review and re-design was also essential. The revised model emerged as outlined in Table 2. 
Table 2. Building a CARPE DIEM process.

\begin{tabular}{|c|c|c|c|}
\hline Activity & Plan & Typically led to & Outcomes \\
\hline $\begin{array}{l}\text { Contact } \\
\text { meeting } \\
\text { with } \\
\text { departments }\end{array}$ & $\begin{array}{l}\text { Course teams outline } \\
\text { their plans for } \\
\text { e-learning design } \\
\text { for their course/ } \\
\text { module to the } \\
\text { CARPE DIEM } \\
\text { facilitator. }\end{array}$ & $\begin{array}{l}\text { Discussion of pedagogy by } \\
\text { course groups. Teaching } \\
\text { \& assessment methods } \\
\text { currently in use surfaced } \\
\text { and discussed. } \\
\text { Facilitator emphasised } \\
\text { the team planning of the } \\
\text { course. }\end{array}$ & $\begin{array}{l}\text { Redesign of course team } \\
\text { plans based on widening } \\
\text { understanding and 'letting } \\
\text { go' of some original ideas. } \\
\text { Groups work together, } \\
\text { sometimes forming a } \\
\text { 'team'; for the first time. }\end{array}$ \\
\hline $\begin{array}{l}\text { CARPE DIEM } \\
\text { two-day } \\
\text { workshop }\end{array}$ & $\begin{array}{l}\text { Intensive two-day } \\
\text { process of activities } \\
\text { and discussion } \\
\text { based on structured } \\
\text { model. }\end{array}$ & $\begin{array}{l}\text { Development of course } \\
\text { designs and e-tivities } \\
\text { posted on the VLE, plus } \\
\text { completion of action } \\
\text { plans. }\end{array}$ & $\begin{array}{l}\text { Learning by the course team, } \\
\text { desire to continue to build } \\
\text { e-tivities on the VLE, and } \\
\text { recommendations to } \\
\text { others. }\end{array}$ \\
\hline $\begin{array}{l}\text { Review and } \\
\text { re-design }\end{array}$ & $\begin{array}{l}\text { Course teams request } \\
\text { more consultation } \\
\text { with CARPE DIEM } \\
\text { team at various } \\
\text { stages of } \\
\text { implementation. }\end{array}$ & $\begin{array}{l}\text { Changes made to course } \\
\text { designs. }\end{array}$ & $\begin{array}{l}\text { Implementation. } \\
\text { Engagement of other } \\
\text { stakeholders in the } \\
\text { department. Impact on } \\
\text { learner experience. }\end{array}$ \\
\hline
\end{tabular}

\section{Outcomes of the CARPE DIEM intervention}

\section{Pre-workshop contact meetings}

These meetings with course teams, before they committed to becoming ADELIE partners, revealed aspects of their culture and practices surrounding pedagogy. Teaching and assessment methods used by the department were surfaced. The pre-meetings enabled the ADELIE team to learn about each course team's needs and modules or programmes they intended to design for and to pre-empt early misunderstandings about e-learning. Some course teams changed their plans at this early stage. One team reorganised their overall course plan before attending the workshop, which made it possible for them to design for collaborative e-learning. Other departments, before attending the workshop, considered possible implications of their new e-learning designs, such as developing tutors' e-moderating skills.

The individualistic culture in university teaching, and how resources for teaching are allocated in departments at Leicester, made commitment of a subject team to a two-day workshop a hurdle to overcome. BDRA offered the Media Zoo physical environment for the workshops (www.le.ac.uk/beyonddistance/mediazoo) at no recharge cost.

Previously, many academics had worked largely alone on developing their courses: very few had experienced the benefits of working with learning technologists and subject librarians in a structured way. Interviews confirmed that bringing the team together to begin planning pedagogy and course development was a valued change in their practice. The process provided opportunities to "thrash out team differences and come together to a team consensus' (L. Inter-Professional Education) and 'real enjoyment and enthusiasm [was] experienced by course teams [preparing for their two-day workshop]' (P. Education).

\section{The CARPE DIEM workshops}

The CARPE DIEM workshops yielded largely positive evaluations by the participating course teams. They reported that determining pedagogic and subject knowledge goals 
collectively for their course was an effective activity for them. They were able to exploit the technological tools provided by the university for e-learning design and delivery better than before, and to make effective choices about task design, resources and technologies. The process was iterative and reflective: at all stages the ADELIE team provided input, insight, feedback and advice, thus increasing the course team's understanding of pedagogy and their technological capability. The workshops were also practical and useful: teams left with at least two online activities, an overall course framework based on networked learning, a much wider and purposeful exploitation of the VLE's features and a clear action plan.

CARPE DIEM did have an impact on our department. So things have moved a lot in the last few months ... in the course spec we specifically put in that we wanted 'proper' online learning and ... staff development in e-learning. (P. Education)

Learning to design e-tivities proved to be a catalyst for shifting participants' understanding of pedagogy. Both interview and observation data revealed their increased understanding, especially in designing to increase learners' engagement with the course, its resources and each other.

We have developed three activities. One of those was developed in the workshop the other two were done afterwards by [colleague's name] and myself. One was on similar lines to the one done in the workshop and the other was a wiki that was ... inspired by some of the discussion in the workshop. (R. Law)

CARPE DIEM is a course design intervention, not a workshop on how to use a VLE. However, in designing e-tivities collaboratively and in context, teams learn about VLE features that may be new to them but fit for their desired pedagogical purpose. These include wikis, blogs and the embedding of sound or video.

Several teams reported a concern of 'being taken over' by others who did not understand the special needs of their subject. However, this fear gradually dissipated over the two days and participants commented that they felt in control of their planning.

We felt we were working with you and we had time to sort out what we wanted to do. (J. Geography)

Post-CARPE DIEM interviews showed that all the subject teams had reflected on the potential and role of e-learning in learning and teaching in ways that they had not considered before. The extent to which this shift was innovative depended on the group's prior knowledge of and experience with e-learning. As one leader of a subject group said of his team:

They were very suspicious before they did the CARPE DIEM. I just wanted them to see what e-learning could do and they are now much more open to doing it. We are going ahead with our design in one of our modules. (P. Education)

One subject team expressed initial scepticism towards e-learning in general and about the possibility of designing for e-learning in their particular course. Following the workshop, the team trialled their e-learning design with one group of postgraduate students, while keeping their traditional distance learning design with another group. The team maintained the designs developed in CARPE DIEM in subsequent iterations of their course and are in the process of embedding e-tivities across other courses in the department, for which they have requested help from BDRA. 
...e-learning has got the potential to make teaching better. I've got some essays that have just come in from the [e-learning design] group and we see a greater maturity of understanding from that group than from the group that have approached it in a more traditional way. (R. Psychology)

Leicester emphasises 'the student experience'. Most subject team academics were unsure whether or how this applied to them, but following CARPE DIEM they showed a greater awareness of students' needs, which they took into account in designing for e-learning.

[CARPE DIEM] really got me to think ... e-learning is more student-centred, doing e-learning is more thinking about the ways that students can approach the material. You know, you're a student and you're starting this activity, what are you going to do, how are you going to do it. (R Media Studies)

I think two elements really; one was the sort of teaching technology we should use. So what we were using and what we weren't using and where we could benefit from using [it]. Well us and the students could benefit from using it. So there was that kind of inspirational side of it but I think there was also that reflective side of it. So we were starting to think well what do we want to try and achieve? We bounced a lot of ideas around and we modified modules, we changed this, we changed that. But what CARPE DIEM allowed us to do as well was to answer well: what do we want people to be getting from this course?

(R. Psychology)

In summary, academic course teams acknowledged the benefits arising from the team approach to course design that CARPE DIEM offered. They worked collegially and finished the workshop with an increased understanding of pedagogy relevant to their disciplines. They learned to make more effective use of VLE features in context and increased their understanding via purposeful, learner-centred and peer-reviewed e-tivities. Teams were willing to try out the new designs in their teaching and felt confident about their ability to generate and integrate more e-tivities into their courses. Each of these aspects contributed to their capability building.

\section{Post CARPE DIEM workshops}

After the CARPE DIEM workshop, when the course teams took their designs back to their departments, their partnership with the ADELIE team continued formally and informally. For example, the ADELIE team was asked to attend meetings with the course teams after a design had been implemented, to advise on adjustments.

Some course teams needed additional support to embed their new designs into routine departmental practices and assessment strategies. Several teams asked for further sessions or advice on designing for e-learning in their specific contexts. BDRA has continued to work closely with participating teams to help them incorporate and pilot changes in design, and to encourage the cascading of these approaches to course design, internally.

Participants reported 'a raised profile for e-learning in the department' and that 'e-learning is being written into [their] staff development plans'. Another subject team developing a blended course for on-campus students reported plans to develop a further course for firstyear students. Other teams reported their intention to develop other courses or modules. While these developments may be linked to a general shift towards acceptance of e-learning at Leicester, CARPE DIEM succeeded in putting the institutional e-learning strategy firmly on the departments' agendas in a meaningful and practical way. 
In fact, this morning we just had another departmental meeting about webcams. There is a small group of us trying to take that forward as well. (P. Applied Linguistics)

Some problems the course teams encountered in implementing their courses have wider implications for the institution. For example, the teams found institutional and departmental allocations of teaching time for online courses challenging.

What we need is ever greater commitment from each School to find more e-moderators.

(L. Inter Professional Education)

To develop and implement further designs for the assessment of student performance, especially in collaborative work, the subject teams need to challenge departmental and traditional practices.

There may be difficulty in getting the department to agree really. Because people tend to be a bit uptight about external examiners. (I. Law)

We interpret these potential disturbances to the system in a positive way: academics are identifying barriers to their capability building and setting a strategic agenda.

\section{Results}

\section{Capability building}

The intervention proved effective and appropriate in building capability in learner-centred e-learning design. Eighty-seven academics were involved in ADELIE. Many Leicester academics found the e-tivities framework acceptable and relevant, and incorporated it into student learning. They confirmed that use of the VLE for learning activities is low-cost and popular with students if instructions are clear and feedback frequent, and e-tivities help to integrate the VLE into the curriculum (Hall 2006).

Those subject teams that did not implement their full design usually curtailed the provision for participatory learning. Typically, these teams had not planned for the provision of teaching time to support online collaboration and maintenance of participative aspects of their design. As a consequence, they re-wrote e-tivities to dispense with discussion forums and other functionality that enabled students to share their work and their ideas. Provision for participative learning implies the allocation of tutor time to e-moderate learners' input as an essential component of effective e-learning. The perceived increase in workload that may occur as a result was a concern for most of the participating teams.

Improved capability at the institutional level was revealed in the second benchmarking exercise. On a scale of 1.0 to 6.0, it showed increases in scores under the two key criteria: 'Instructional design/pedagogy' increased from 2.0 in 2006 to 4.0 in 2007, and 'Learning materials' increased from 3.0 to 4.0 (see Table 1 ).

Particular attention was paid during the intervention to building 'design teams', given the climate for crossing barriers in the service of capability building for the future (Whitchurch 2007). In half the subject teams, CARPE DIEM participants presented at the pre-meeting as a 'team', with common goals, shared understanding and trust. They knew each other very well and played to their strengths. The outputs at the end of the workshop were generally well advanced as a result. The other teams were more heterogeneous. Some academics had been given the task of 'writing a module', with few or no links to the rest of the programme or their colleagues. In some cases, this job was offered to part-time lecturers, who were typically 
less integrated into the team and more concerned than full-time staff about the allocation of hours available to design the course. One group included 'consultants' who were 'hired to write a module' and were not part of the department. In all of these cases, the CARPE DIEM process provided an opportunity to forge new and relevant relationships and to ensure the learning programme had, at least, a shared mission and approach, but the intervention was not by itself sufficient to transform the disparate groups into coherent teams.

No brand new subject teams were formed as a result of working through the CARPE DIEM process, but the data showed that participants behaved and designed differently afterwards. They shared more common ground than before in terms of design and pedagogy, and they knew each other better. They were more aware of the importance of a team approach to course design, knew how pedagogical, technological and information specialists could help them at the early stages of design, had a better understanding of their departmental programme as a whole and of how various modules linked to each other. They understood how, by designing better, they could make the programme more coherent, consistent, and participative and thus offer a better experience for their learners. This was a positive start to capability building.

There was less success in integrating librarians into subject teams. Librarians attended the CARPE DIEM workshops and productively contributed. They created e-tivities of their own, which were used either as part of the main team's design or within the Library's own resources. The Library is now considering an approach based on the CARPE DIEM model, to offer enhanced support to distance learners.

Learning technologists, on the other hand, developed a lasting, context-sensitive link to each course team, which generated useful synergies for ongoing help, advice and engagement with departmental academic and support staff. Requests for help from learning technologists by academics have increased dramatically.

\section{Discussion}

\section{Further capability building}

The CARPE DIEM process may have begun the capability building that the ADELIE Pathfinder project was seeking. There is acceptance of the process within the university. The action research has enabled us to incorporate change in e-learning design into the university's priorities. Beyond the university the CARPE DIEM process has demonstrated its usefulness and acceptability in the wider HE sector through further externally funded projects and inter-institutional collaborative work.

Small subject teams, CARPE DIEM 'graduates', spread the word within their own department. To date, seven departments have requested or received a second CARPE DIEM for another module or programme and one department has received four. Encouragement to apply for CARPE DIEM workshops across departments happens visibly within formal committee structures, through support from senior managers and resource-holders and through staff development activities. It is difficult to determine how much informal mention occurs but new lecturers, especially those with responsibility for teaching new courses, approach BDRA very quickly upon their appointment.

In 2008 a specialist distance learning (DL) unit associated with a new DL strategy is being set up to provide design and production help for subject teams who wish to undertake curriculum design and delivery through distance learning. The strategy and resourcing includes provision for CARPE DIEM workshops and design support.

In October 2007, BDRA started a 12-month Academy-funded research project called Assessment \& Disciplines: Developing E-tivities Research (ADDER). ADDER focuses on 
the work of the Re-Engineering Assessment Practices project (www.reap.ac.uk) and its key principles. BDRA is incorporating the latest research-into-practice approach to assessment and feedback into CARPE DIEM workshops thus demonstrating its ability to respond and adapt.

Early in 2008, the Academy-funded CHEETAH (Change by Embedding E-learning in Teaching Across HEIs) project began. The purpose of CHEETAH is to transfer the CARPE DIEM model to six partner institutions, to help them develop a fresh but sustainable approach to capability building in e-learning design. CHEETAH is enabling BDRA to train more CARPE DIEM facilitators and will contribute to transferring and scaling up the process. Through evaluation and feedback it will continue to build on and refine the CARPE DIEM design. As part of CHEETAH, collaboration with other Pathfinders has begun.

By May 2008, 20 CARPE DIEM workshops had taken place at Leicester and 17 at other UK institutions; 300 staff, including course teams, subject librarians, learning technologists and staff developers had taken part.

\section{Critique and limitations}

This paper has focused on CARPE DIEM workshops for capability building at Leicester and beyond. The e-learning strategy that provided a driving force for these developments is ending its three-year cycle and is under review. The wide variety of small positive impacts on staff capability may well ensure its continuation at Leicester, enabling BDRA to look at institutional-wide issues in the medium term. This paper does not report on the ongoing evaluation needed to establish the impact on student learning from the new designs, many of which are being delivered during 2008. Clearly this is a longer-term project and the action-research loops will gradually spiral wider as we obtain feedback from the students about their experience. At present a staff member plays the role of naïve user (called a 'reality checker') and attends the second day of CARPE DIEM workshops to test the new online e-tivities and offer feedback to the design team. In future BDRA expects to offer this role to students to increase their involvement throughout the process

\section{Conclusion}

The CARPE DIEM process works well at Leicester, having resulted in documented examples of improved course design and implementation. The model is stable and adaptable enough to accommodate new priorities and a wide variety of disciplines. It builds teams within and across professional groups and it offers a capability building route for e-learning design.

The CARPE DIEM model is currently being successfully transferred to other HEIs that are learning from each other. Further research will establish whether the model makes a greater or lesser contribution to capability building in universities with cultures, structures or priorities that differ from Leicester's. However, initial soundings from the ADDER and CHEETAH projects, involving CARPE DIEM processes with 14 course teams at 10 HEIs, are very encouraging.

As the use of VLEs changes to accommodate a much wider range of personalised technologies, so the nature of e-tivities designed within CARPE DIEM workshops may alter. BDRA expects that the basic premise and principles of this intervention will take it into capability building for the longer term. If others try out the CARPE DIEM model, please report back. 


\section{Acknowledgements}

Our thanks to the Higher Education Academy for their funding of ADELIE; to Roger Dence and Professor David Hawkridge (BDRA) for their support with the research and comments on this paper; to Jaideep Mukherjee (BDRA) for his work on benchmarking; to the academic subject teams at Leicester who gave their precious time and energy to try out the CARPE DIEM process; and to Sharon Waller (Anglia Ruskin University), Janet Hanson (Bournemouth University), Gillian Roberts, Linda Creanor and Kate Lennon (Caledonian Business School) and their course teams, colleagues and researchers for the early work on the CARPE DIEM model.

\section{References}

Anderson, I., P. Bullen, J. Alltree, and H. Thornton. 2008. CABLE: An approach to embedding blended learning in the curricula and across the institution. Reflecting Education 4, no. 1: 30-41.

Armellini, A., and S. Jones. 2008. Carpe Diem: Seizing each day to foster change in e-learning design. Reflecting Education 4, no. 1: 17-29.

Ask, B. 2007. Rethinking university learning, environments and methods. In Proceedings of Online Educa Conference, ed. M. Achten, S. Serman, and M. Gernemann, 61-3, November 28-30, in Berlin. Berlin: ICWE GmBH.

Bhattacharya, B., J. Cowan, and E. Weedon. 2000. Action research: A means to more effective teaching and learning. Innovations in Education and Training International 37: 314-22.

Becher, T., and P.R. Trowler. 2001. Academic tribes and territories. 2nd ed. Buckingham: SRHE/ Open University Press.

Beetham, H., and R. Sharpe. 2007. An introduction to rethinking pedagogy. In Rethinking pedagogy for the digital age, ed. H. Beetham and R. Sharpe. London: Routledge.

Benfield, G. (2008) Oxford Brookes University, Pathfinder Briefing Paper 2: Course Redesign Intensives. https://mw.brookes.ac.uk/download/attachments/7899009/Briefing2 BrookesCourseDesign+.pdf?version=1.

Biggs, J., and C. Tang. 2007. Teaching for quality learning. 3rd ed. Buckingham: SRHE/Open University Press.

Eden, C., and C. Husham. 1996. Action research for management research. British Journal of Management 7: 91-5.

Flemming, M., and D. Rutherford. 1985. Sources of academic resistance. In The future for higher education, ed. D. Jaques and J. Richardson, 88-96. Guildford: Society for Research in Higher Education and NFER-Nelson.

Hall, R. 2006. Delivering what students say they want on-line: Towards academic participation in the enfranchisement of e-learners? Electronic Journal of E-learning 4, no. 1. www.ejel.org/ volume-4/v4-i1/hall-richard.pdf.

Hamel, G., and L. Valikangas. 2003. The quest for resilience. Harvard Business Review September: $52-63$.

Hannan, A. 2005. Innovating in higher education: Contexts for change in learning technology. British Journal of Educational Technology 36, no. 6: 975-85.

HEFCE. 2005. Higher Education Funding Council England, Strategy for e-learning, March. http:// www.hefce.ac.uk/pubs/hefce/2005/05_12/.

Hunt, L. 2006. A community development model of change. In The realities of change in higher education, ed. L. Hunt, A. Bromage and B. Tomkinson, 64-77. London and New York: Routledge.

Jaques, D., and G. Salmon. 2006. Learning in groups: A handbook for face-to-face and online environments. London and New York: Routledge.

Jenkins, A. 1996. Discipline-based educational development. International Journal for Academic Development 1, no. 1: 50-62.

Laurillard, D. 2007. Foreward to Rethinking pedagogy for a digital age, ed. H. Beetham and R. Sharpe. London: Routledge.

Lomax, P. 1994. Action research for managing change. In Improving educational management through research and consultancy, ed. N.D. Bennet, R. Glatter, and R. Levacic, 102-16. London: Chapman.

Malone, E. 2004. Seize the day. Chartered Institute of Library and Information Professionals. Update Magazine 3. cilip.org.uk/publications/updatemagazine/archive/archive2004/september/ article3.htm. 
Renwick, W. 1992. Distance education in dual mode universities. In Distance teaching in single and dual mode universities, ed. I. Mugridge, 149-52. Vancouver: Commonwealth of Learning.

Salaman, G., and D. Asch. 2003. Strategy and capability: Sustaining organizational change. Oxford: Blackwell.

Salmon, G. 2002. E-tivities: The key to active online learning. London and New York: Routledge. 2003. Any time this century: An exploration of achieving more with less for implementing e-learning. Paper presented at 'Strategic Responses to Change', April, in Cambridge. http:// www.atimod.com/research/presentations2003.shtml.

. 2004. E-moderating: The key to teaching and learning online. 2nd ed. London and New York: Routledge.

2005. Flying not flapping: A strategic framework for e-learning and pedagogical innovation in higher education institutions. ALT-J, Research in Learning Technology 13, no. 3: 201-18.

Salmon, G., and M. Nie. 2008. Doubling the life of ipods. In Podcasting for learning in universities, ed. G. Salmon and P. Edirisingha. Buckingham: Open University Press/SHRE.

Sharpe, R., G. Benfield, and R. Francis. 2006. Implementing a university e-learning strategy: Levers for change within academic schools. ALT-J, Research in Learning Technology 14, no. 2: 135-51.

Siddiqui, N., and G. Roberts. 2004. Electronic marketing online - Reflections and future developments. Paper presented at theBEST Conference: Reflections on teaching: The impact of learning, April 14-16, in Edinburgh.

Tumminello, W. 2004. Exploring storyboarding. New York: Delmar Learning.

Whitchurch, C. 2007. Shifting identities, blurring boundaries: The changing roles of professional managers in higher education. Paper presented at the SRHE Conference, December 11-13, in Brighton. 